\title{
Influence of CNF content on microstructure and fracture toughness of CNF/alumina composites
}

\author{
Naoki UEDA, Tomohiko YAMAKAMI, Tomohiro YAMAGUCHI, Yuki USUI, ${ }^{*}$ \\ Kaoru AOKI, ${ }^{*}$ Morinobu ENDO, Naoto SAITO** and Seiichi TARUTA ${ }^{\dagger}$ \\ Faculty of Engineering, Shinshu University, 4-17-1 Wakasato, Nagano 380-8553, Japan \\ *Shinshu University School of Medicine, 3-1-1 Asahi, Matsumoto, Nagano 390-8621, Japan \\ ** Department of Applied Physical Therapy, Shinshu University School of Health Sciences, \\ 3-1-1 Asahi, Matsumoto, Nagano 390-8621, Japan
}

\begin{abstract}
Dense 0.4-5.0 wt \% carbon nanofiber (CNF)/alumina composites were fabricated by plasma activated sintering. The microstructure-particularly the CNFs distribution-of composites containing different amounts of CNFs was observed in detail, and the influence of the additive amounts of CNF on the microstructure and the fracture toughness of the composites were investigated. The ratio of CNFs distributed individually in the composites decreased with an increase in the addition of CNFs, and the other CNFs formed bundles; notably three-quarters of the CNFs formed bundles in the $5.0 \mathrm{wt} \% \mathrm{CNF} /$ alumina composite. The alumina grain size distribution of the composites became narrower to smaller grain size side and the average alumina grain size of the composites decreased with an increase in the addition of CNFs from 0.4 to $1.6 \mathrm{wt} \%$. However, the average alumina grain size of the composites did not vary greatly with an increase in the addition of CNFs from 1.6 to 5.0 wt \%, because the CNF bundles formed in the 2.5 and $5.0 \mathrm{wt} \% \mathrm{CNF}$ /alumina composites lowered the grain growth retardation effect of the CNFs. The $1.6 \mathrm{wt} \% \mathrm{CNF}$ /alumina composite exhibited the highest fracture toughness, because three-fifths of the CNFs distributed individually and uniformly in alumina grain boundaries.
\end{abstract}

(C)2014 The Ceramic Society of Japan. All rights reserved.

Key-words : Alumina, Carbon nanofibers, Composite, Fracture toughness, Microstructure

[Received August 23, 2013; Accepted February 1, 2014]

\section{Introduction}

Carbon nanotubes (CNTs) have incredible mechanical properties and a high aspect ratio, ${ }^{1)-8)}$ so it seems that CNTs are superior reinforcement fibers for the improvement of the mechanical properties of ceramic materials. With that aim in mind for alumina ceramics, we have combined the high-dispersion-treated carbon nanofibers (CNFs), which are a type of multi-walled CNTs, with alumina. ${ }^{9)}$ In the study, we found that the fracture toughness of the CNF/alumina composites increased with a decrease in the average alumina grain size of the composites, regardless of CNF content in the range of $0.4-2.5 \mathrm{wt} \% .^{9)}$ In these composites, CNFs were observed bending along alumina grain boundaries. The dependence of the fracture toughness of the composites on the average alumina grain size could be explained by the bridging and/or pull-out of the bended CNFs. That is, the number of bendings per CNF increased as the average alumina grain size of the composites decreased. As the number of bendings increased, the resistance for bridging and/or pull-out of the CNFs increased. Consequently, the fracture toughness of the composites increased with a decrease in the average alumina grain size. On the other hand, the CNFs were gathered at the same sites in the grain boundaries and formed bundles through the grain growth of alumina during sintering, especially in the composites containing larger amounts of CNFs. By forming CNF bundles, the number of CNFs giving rise to the essential effect for bridging and/or pull-out was reduced, and the resistance for bridging and/or pull-out of CNFs in the composites did not

Corresponding author: S. Taruta; E-mail: staruta@ shinshu-u.ac.jp always increase with an increase in the additive amount of CNFs. Consequently, the fracture toughness of the composite was not greatly influenced by the additive amount of CNFs.

Some reports ${ }^{10)-16)}$ on CNT/alumina composites have shown that the fracture toughness of composites does not always greatly increase with an increase in the additive amount of CNTs. For example, Yamamoto et al. ${ }^{12)}$ reported that the fracture toughness of the CNT/alumina composites decreased with increasing MWCNTs content from $0-10$ mass $\%$ because of the presence of CNT aggregates. Hirota et al. ${ }^{14)}$ reported that the fracture toughness of the $3-5$ vol \% CNF/alumina composites showed a slight increase compared to that of monolithic alumina. Maensiri et al. ${ }^{15)}$ reported that the fracture toughness of the $\mathrm{CNF}$ /alumina composites increased with a slight dependency on the additive amount of CNFs, and a $13 \%$ increase in fracture toughness compared to monolithic alumina was obtained in the $2.5 \mathrm{vol} \% \mathrm{CNF} /$ alumina composite.

In order to achieve a further improvement in the fracture toughness of CNT/alumina composites by the addition of a larger amount of CNTs, the CNTs should distribute individually and uniformly in the composites. However, the influence of CNTs distribution on microstructure development and the mechanical properties of the CNT/alumina composites containing a different amount of CNTs has not yet been reported in detail.

In our first paper ${ }^{9)}$ on the CNF/alumina composites, we reported as mentioned above that the $0.4-2.5 \mathrm{wt} \% \mathrm{CNF} /$ alumina composites were fabricated using the high-dispersion-treated CNFs and the influence of the addition of the CNFs on the densification, microstructure development and mechanical properties of the composites were investigated. In our second paper, ${ }^{17)}$ 
we reported that the $0.4 \mathrm{wt} \% \mathrm{CNF} /$ alumina composites were fabricated using CNFs acid-treated for $0.5,1$ and $5 \mathrm{~h}$. The CNFs acid-treated for $0.5 \mathrm{~h}$ dispersed more uniformly in the composite than the high-dispersion-treated CNFs and the composite containing the CNFs acid-treated for $0.5 \mathrm{~h}$ had a smaller average alumina grain size and higher fracture toughness. Now, in this study, the CNFs acid-treated for $0.5 \mathrm{~h}$ were mixed with alumina and the 0.4-5.0 wt \% CNFs/alumina composites were fabricated by plasma activated sintering (PAS). The microstructuresparticularly the CNFs distributions-of the composites containing different amount of CNFs were qualitatively estimated by observing the backscattered electron (BSE) images of polished surfaces of these composites under accelerating voltage of $1 \mathrm{kV}$ and were quantitatively estimated by observing the scanning electron microscopic images of polished and chemically etched surfaces of these composites. Such qualitative and quantitative estimations have neither been tried in our previous studies ${ }^{9), 17)}$ nor in other studies on $\mathrm{CNF} /$ ceramics composites and were carried out for the first time by us in this study. The influence of the additive amount of the CNFs on CNF distribution, alumina grain size distribution and fracture toughness of the composites fabricated by PAS were investigated.

\section{Experimental procedure}

\subsection{Preparation of the acid-treated CNFs and the composites}

CNFs (VGCF-S; diameter: $100 \mathrm{~nm}$, length: 10-20 $\mu \mathrm{m}$, Showa Denko, Japan) were acid-treated for $0.5 \mathrm{~h}$ using an acid mixture (conc. $\mathrm{H}_{2} \mathrm{SO}_{4}$ : conc. $\mathrm{HNO}_{3}=3: 1 \mathrm{v} / \mathrm{v}$ ) under application of ultrasonic agitation in order to prepare the hydrophilic CNFs and improve interfacial compatibility between CNFs and the alumina grain. Raman spectra of the CNFs showed that defects were induced on them by the acid-treatment for $0.5 \mathrm{~h}^{17}{ }^{17}$

The acid-treated CNFs were ultrasonically dispersed in ethanol solution dissolving a small amount of polyvinylbutyral (PVB) as a dispersant. The CNF-ethanol suspensions were quietly kept for 3 days to allow the remaining bundles or agglomerates of CNF sediment in the bottom layer of the suspensions. Then, the upper layer of the suspensions was elutriated to obtain well dispersed CNF suspensions. These were mixed with high-purity alumina powder (TM-DAR; purity: 99.99\%; average particle size: $0.1 \mu \mathrm{m}$; Taimei Chemicals, Japan) by ball-milling for $24 \mathrm{~h}$. The obtained slurries were dried and then passed through a 100-mesh sieve. In this way, the powder mixtures containing $0.4-5.0 \mathrm{wt} \% \mathrm{CNFs}$ were prepared.

The powder mixtures were consolidated by plasma activated sintering (Ed-PAS, ELENIX) at $1300-1525^{\circ} \mathrm{C}$ for $80 \mathrm{~s}$ in a vacuum. They were put under an uniaxial pressure of $50 \mathrm{MPa}$ during PAS, except for the powder mixture containing $1.6 \mathrm{wt} \%$ $\mathrm{CNFs}$ sintered by $\mathrm{PAS}$ at $1375^{\circ} \mathrm{C}$, which was put under an uniaxial pressure of $40 \mathrm{MPa}$ during PAS. The heating rate of PAS was $300^{\circ} \mathrm{C} / \mathrm{min}$.

\subsection{Estimation of composites}

The bulk densities of the composites were measured using the Archimedes method. The relative densities were calculated using the bulk densities of the composites and the theoretical densities of alumina $\left(3.987 \mathrm{~g} / \mathrm{cm}^{3}\right)$ and VGCF-S $\left(2.0 \mathrm{~g} / \mathrm{cm}^{3}\right)$. The microstructures of the composites were observed using a scanning electron microscope (SEM, S-4100 or SU-8000, Hitachi).

The fracture toughness was measured using the Vickers indentation tester (VMT-7, MATSUZAWA). An 196N load was applied on the polished surface for $10 \mathrm{~s}$. For the composites which crack tipping were observed, a lower indentation load $(98 \mathrm{~N})$ was applied on the polished surface. The crack-to-indent ratios $(c / a)$ were larger than 2.5 in every indentation, where $c$ is the half-length of the surface radial crack and $a$ is the halfdiagonal length of the Vickers indent. This means cracks propagated in the composites were median cracks. ${ }^{18)-20)}$ So the fracture toughness was calculated by Miyoshi's formula. ${ }^{21)}$

The alumina grain sizes of the composites were measured using the line-intercept method. ${ }^{22}$ ) The measured individual grain size was the maximum length of the grain, which is described as tangent diameter, ${ }^{23), 24)}$ in the specified direction. The average alumina grain size was determined from the sizes of more than 200 grains. The details for preparation of the specimen were shown in our previous reports.9),17)

\section{Results and discussions}

\subsection{Densification}

The relative densities of the $0.4-5.0 \mathrm{wt} \% \mathrm{CNF} /$ alumina composites and monolithic alumina ceramic are shown in Fig. 1. Regardless of the additive amount of CNFs, the relative densities of the composites sintered by PAS at $1375^{\circ} \mathrm{C}$ for $80 \mathrm{~s}$ were more than $99 \%$. In addition, the $0.4-1.6 \mathrm{wt} \% \mathrm{CNF} /$ alumina composites sintered by PAS at 1300 and $1450^{\circ} \mathrm{C}$, and the 2.5 and $5.0 \mathrm{wt} \% \mathrm{CNF} /$ alumina composites sintered by PAS at 1450 and $1525^{\circ} \mathrm{C}$ were densified to a relative density of more than $99 \%$. On the other hand, the relative densities of the composites sintered in vacuum at $1350^{\circ} \mathrm{C}$ for $2 \mathrm{~h}$ decreased drastically with an increase in the additive amount of CNFs, as shown in Fig. 1. Similar results were obtained for the composites sintered in vacuum at $1450^{\circ} \mathrm{C}$. Though the holding time of PAS was 100 times shorter than that of vacuum sintering, even the composites containing $5.0 \mathrm{wt} \% \mathrm{CNFs}$ were densified to near the full density by PAS. These results indicate that the densification rate of the composites was accelerated by the unique sintering process of PAS.

\subsection{Microstructures}

SEM images of the chemically etched surfaces of the 0.4 $5.0 \mathrm{wt} \% \mathrm{CNF} /$ alumina composites sintered by PAS at $1375^{\circ} \mathrm{C}$ for $80 \mathrm{~s}$ are shown in Fig. 2. The chemical etching for the composites of which the surfaces were polished to a mirror finish was

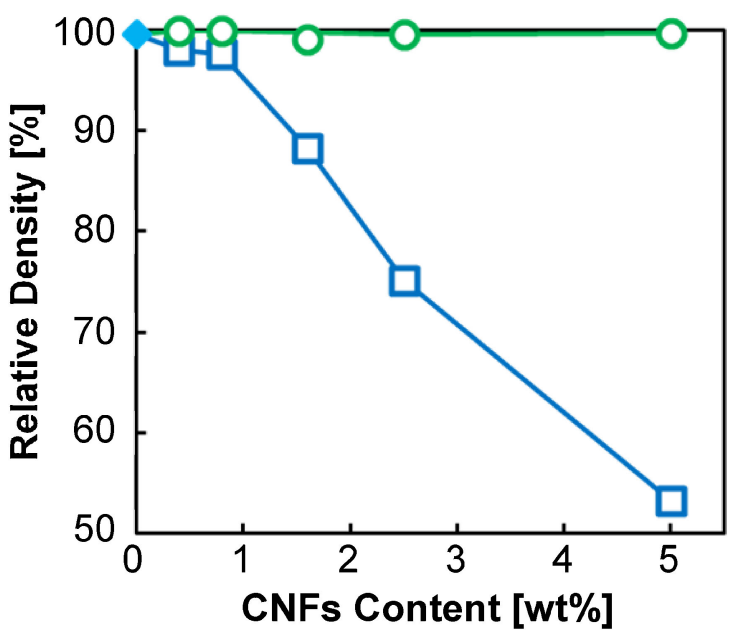

Fig. 1. Relative densities of $(\bigcirc)$ the $0.4-5.0 \mathrm{wt} \% \mathrm{CNF} /$ alumina composites sintered by PAS at $1375^{\circ} \mathrm{C}$ for $80 \mathrm{~s},(\square)$ the composites sintered in vacuum at $1350^{\circ} \mathrm{C}$ for $2 \mathrm{~h}$ and $(>)$ monolithic alumina sintered in air at $1300^{\circ} \mathrm{C}$ for $2 \mathrm{~h}$ and then treated by HIP. 

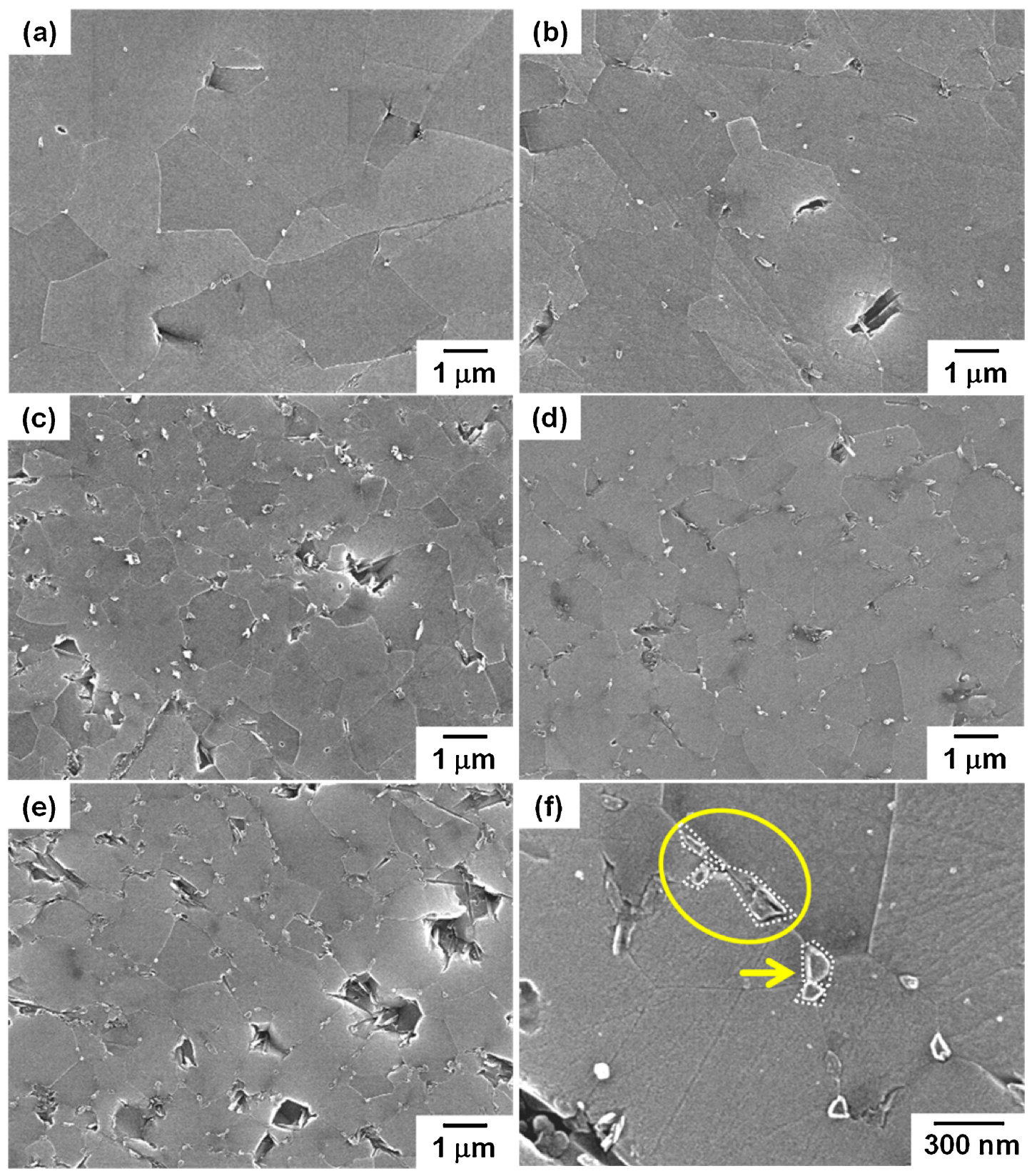

(f)

Fig. 2. SEM images of chemically etched surfaces of the (a) 0.4 , (b) 0.8 , (c) 1.6 , (d) 2.5 and (e,f) $5.0 \mathrm{wt} \%$ CNFs/alumina composites sintered by PAS at $1375^{\circ} \mathrm{C}$ for $80 \mathrm{~s}$. The circle and arrow in (f) indicate bundles consisting of three and two CNFs, respectively.

carried out in conc. $\mathrm{H}_{3} \mathrm{PO}_{4}$ at $140^{\circ} \mathrm{C}$ for $0.5-1 \mathrm{~h}$. By this etching, not only alumina grain boundaries but also CNFs appeared. The alumina grain sizes became smaller as the additive amount of CNFs increased from 0.4 to $1.6 \mathrm{wt} \%$. However, no such obvious difference in alumina grain sizes was observed in the 1.6-5.0 wt $\% \mathrm{CNF} /$ alumina composites. Agglomerates of CNFs were not observed in the $0.4-2.5 \mathrm{wt} \% \mathrm{CNF} /$ alumina composites, but a few agglomerates $5-10 \mu \mathrm{m}$ in size were observed in the $5.0 \mathrm{wt} \%$ $\mathrm{CNF} /$ alumina composites. As indicated by an arrow and a circle in Fig. 2(f), two or three CNFs were gathered at the same site in the composites, namely at the grain boundary, which shows that these CNFs formed bundles. In the 0.4 and $0.8 \mathrm{wt} \% \mathrm{CNF} /$ alumina composites sintered at $1300-1450^{\circ} \mathrm{C}$, some $\mathrm{CNFs}$ were observed in the alumina grains. Then, the number of CNFs distributed in the alumina grains and at the alumina grain bound- aries was counted using SEM photographs of the chemically etched surface of the composites, and the ratio for each composite was determined. The total number of CNFs was at least 370 . As the results, in the 0.4 and $0.8 \mathrm{wt} \% \mathrm{CNF} /$ alumina composites sintered at $1375^{\circ} \mathrm{C}, 17$ and $11 \%$ of the CNFs entered alumina grains, respectively, while in the $1.6,2.5$ and $5.0 \mathrm{wt} \% \mathrm{CNF} /$ alumina composites sintered at $1375^{\circ} \mathrm{C}$, only 4,3 and $2 \%$ of the $\mathrm{CNFs}$ entered alumina grains, respectively. In addition, in the $0.4 \mathrm{wt} \% \mathrm{CNFs}$ /alumina composite sintered at 1300 and $1450^{\circ} \mathrm{C}$, 14 and $20 \%$ CNFs entered alumina grains, respectively.

The frequency of solo CNFs and CNF bundles distributed in the $0.4-5.0 \mathrm{wt} \% \mathrm{CNF} /$ alumina composites sintered at $1375^{\circ} \mathrm{C}$ for $80 \mathrm{~s}$ are shown in Fig. 3. The number of solo CNFs and CNF bundles consisting of two, three and more than four CNFs was counted using SEM photographs of the chemically etched surface 


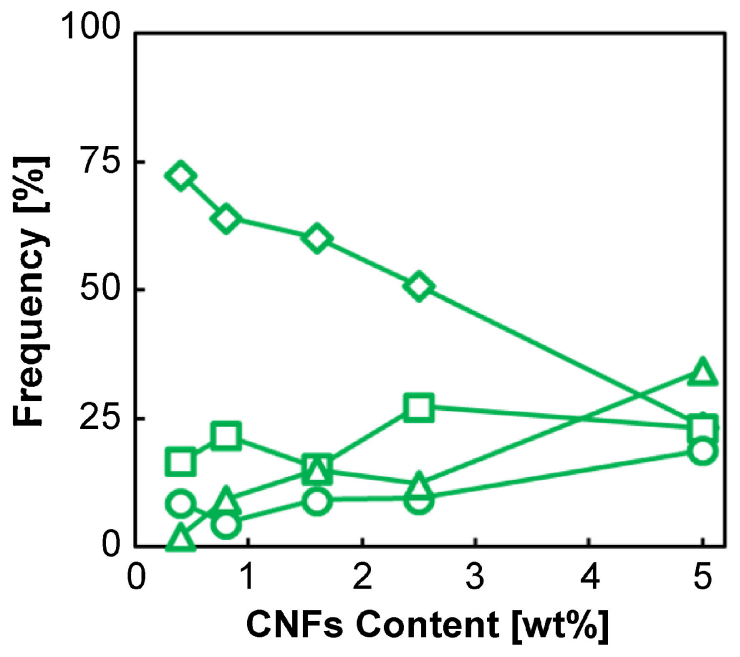

Fig. 3. Frequency of $(\diamond)$ solo CNF and CNF bundles consisting of $(\square)$ two, $(\bigcirc)$ three and $(\triangle)$ more than four CNFs distributed in the 0.4$5.0 \mathrm{wt} \% \mathrm{CNF} /$ alumina composites sintered by PAS at $1375^{\circ} \mathrm{C}$ for $80 \mathrm{~s}$. of the composites, and the frequencies were determined from the ratios of the number of solo CNFs and CNF bundles consisting of two, three and more than four CNFs to the total number of CNFs. As the results, the frequencies of solo CNFs distributed in the $0.4,0.8,1.6,2.5$ and $5.0 \mathrm{wt} \% \mathrm{CNF} /$ alumina composites were 73 , $64,60,51$ and $24 \%$, respectively. This means that more than three-fifths the number of CNFs were distributed individually in the $0.4-1.6 \mathrm{wt} \% \mathrm{CNF} /$ alumina composites, half the number of CNFs were distributed individually in the $2.5 \mathrm{wt} \% \mathrm{CNF} /$ alumina composite, and only a quarter the number of CNFs was individually distributed in the $5.0 \mathrm{wt} \% \mathrm{CNF} /$ alumina composite. In this way, the frequency of solo CNFs decreased with an increase in the additive amount of CNFs; in reverse, the frequency of CNF bundles increased.

BSE images of the 0.4-5.0 wt \% CNF/alumina composites are shown in Fig. 4. The composites were polished by ion-milling and were observed using an electron beam under an accelerating voltage of $1 \mathrm{kV}$ without coating of the conductive films. Each alumina grain was confirmed by the channeling contrast of the backscattered electrons. Though the dark areas in the BSE images
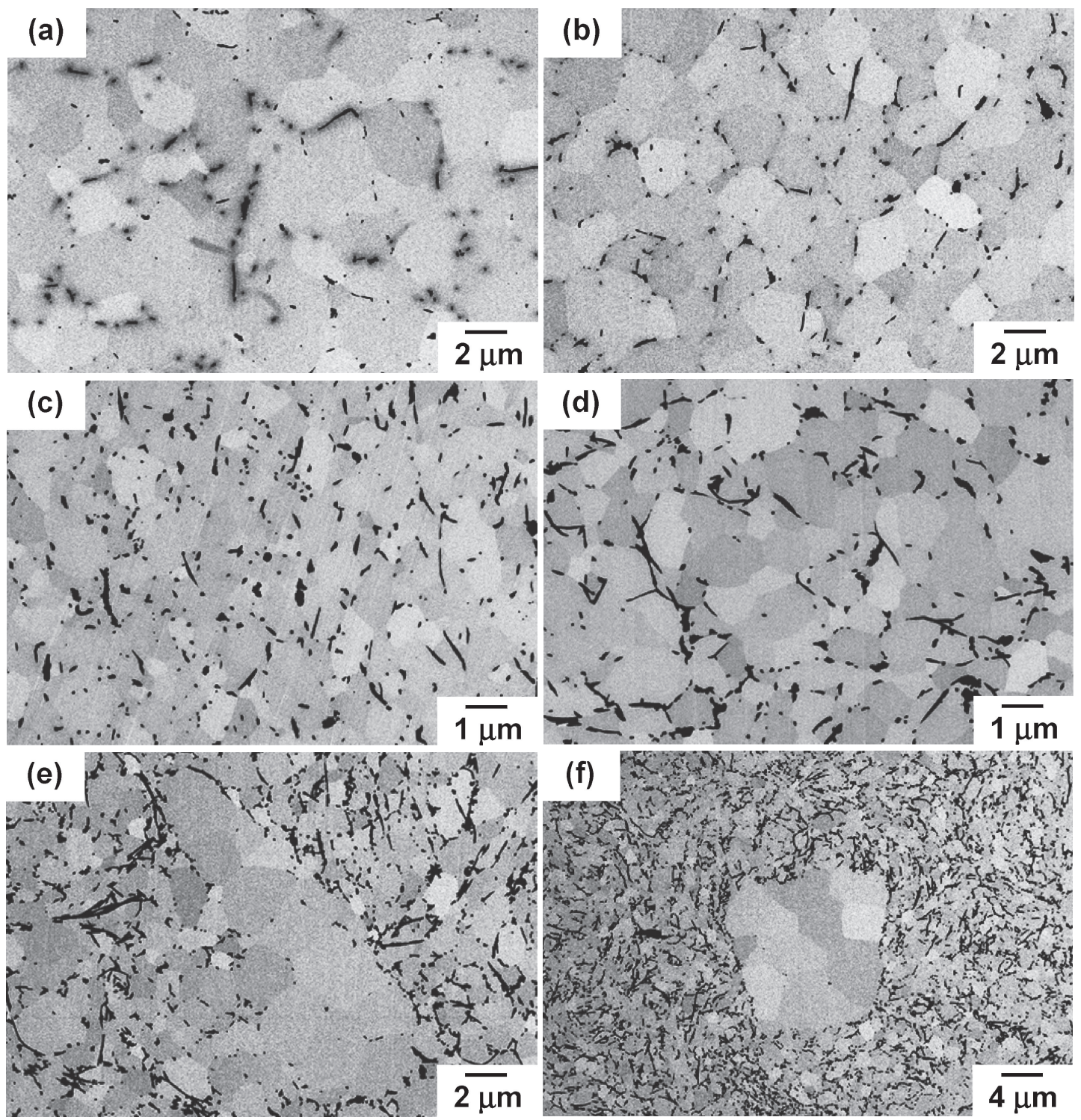

Fig. 4. SEM images of ion-milled surface of the (a) 0.4 , (b) 0.8 , (c) 1.6 , (d) 2.5 and (e,f) $5.0 \mathrm{wt} \% \mathrm{CNF} /$ alumina composites sintered by PAS at $1375^{\circ} \mathrm{C}$ for $80 \mathrm{~s}$. 

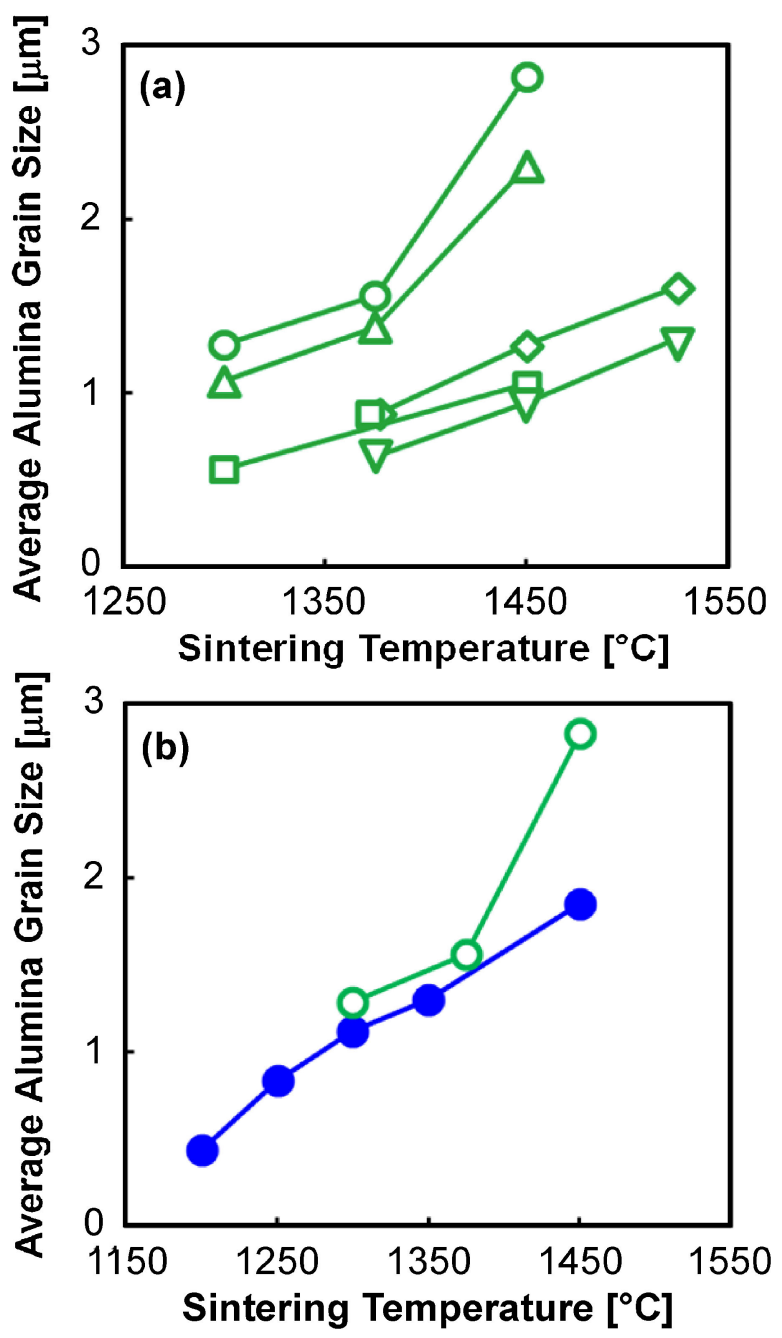

Fig. 5. (a) Average alumina grain sizes of the $(\bigcirc) 0.4,(\triangle) 0.8$, $(\square)$ $1.6,(\diamond) 2.5$ and $(\nabla) 5.0 \mathrm{wt} \% \mathrm{CNF} /$ alumina composites sintered by PAS at various temperatures for $80 \mathrm{~s}$. (b) Average alumina grain size of the 0.4 $\mathrm{wt} \% \mathrm{CNF} /$ alumina composites $(\bigcirc)$ sintered by PAS at various temperatures for $80 \mathrm{~s}$ and $(\mathcal{)})$ sintered in vacuum at various temperatures for $2 \mathrm{~h}$ and then treated by HIP.

of the CNF/alumina composites show either pore or $\mathrm{CNF}$, most dark areas were CNFs because these composites contained few pores. In the 0.4-1.6 wt \% CNF/alumina composites, uniform dispersed dot-like and line-like dark areas were observed and a lot of them were around $100 \mathrm{~nm}$ in diameter and width, which corresponded to the diameter of the CNF. This resulted from the individual and uniform distribution of more than threefifths of the CNFs in the composites. On the other side, there were two kinds of region in the 2.5 and $5.0 \mathrm{wt} \% \mathrm{CNF}$ /alumina composites. One was a region where only a few CNFs were distributed and the other was a region where many CNFs were distributed. In the regions where a few CNFs were distributed, many dark areas were dot-like with sizes of around $100 \mathrm{~nm}$. Such regions in the $5.0 \mathrm{wt} \% \mathrm{CNF} /$ alumina composite appeared clearly and were much wider than those in the $2.5 \mathrm{wt} \% \mathrm{CNF} /$ alumina composite. And alumina grains in such regions grew much larger than those in the other regions, especially, it was remarkable in the $5.0 \mathrm{wt} \% \mathrm{CNF} /$ alumina composite. In the regions where many CNFs were distributed, many dot-like and line-like dark areas were larger than $100 \mathrm{~nm}$, which means that they were CNF bundles. The formation of such CNF bundles and the existence of

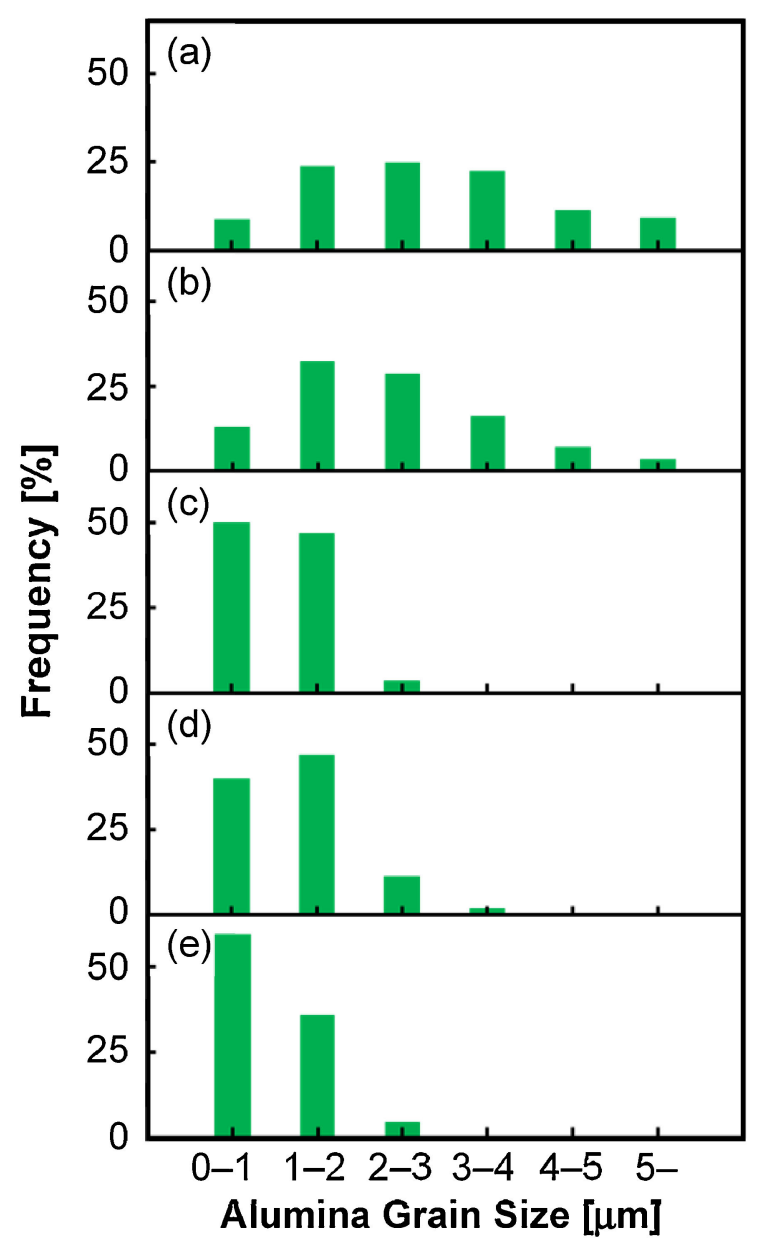

Fig. 6. Alumina grain size distributions of the (a) 0.4 , (b) 0.8 , (c) 1.6, (d) 2.5 and (e) $5.0 \mathrm{wt} \% \mathrm{CNF} /$ alumina composites sintered by PAS at $1450^{\circ} \mathrm{C}$ for $80 \mathrm{~s}$.

these two regions suggest that the 2.5 and $5.0 \mathrm{wt} \% \mathrm{CNF}$ s could not be uniformly mixed with alumina powder by conventional ball-milling. In addition, in the regions where many CNFs were distributed, the CNFs migrated with the alumina grain boundaries during grain growth of alumina and then formed bundles. Such non-uniform mixing and formation of $\mathrm{CNF}$ bundles were remarkable for the $5.0 \mathrm{wt} \% \mathrm{CNF} /$ alumina composites.

The average alumina grain sizes and alumina grain size distributions of the $0.4-5.0 \mathrm{wt} \% \mathrm{CNF} /$ alumina composites are shown in Figs. 5 and 6, respectively. While the average alumina grain size of the 0.4 and $0.8 \mathrm{wt} \% \mathrm{CNF} /$ alumina composites increased rapidly with an increase in sintering temperature from 1375 to $1450^{\circ} \mathrm{C}$, that of the $1.6-5.0 \mathrm{wt} \% \mathrm{CNF}$ /alumina composites increased gradually with an increase in sintering temperature from 1375 to $1525^{\circ} \mathrm{C}$. As the addition of CNFs increased from 0.4 to $1.6 \mathrm{wt} \%$, the alumina grains with a size of more than $3 \mu \mathrm{m}$ decreased and the grain size distribution became narrower, as shown in Fig. 6. In the $1.6 \mathrm{wt} \% \mathrm{CNF} /$ alumina composite, the size of the alumina grains was below $3 \mu \mathrm{m}$. On the other side, the grain size distribution of the $2.5 \mathrm{wt} \% \mathrm{CNF}$ /alumina composite extended to a larger grain size side compared with that of the $1.6 \mathrm{wt} \% \mathrm{CNF} /$ alumina composite, and that of the 5.0 $\mathrm{wt} \% \mathrm{CNF} /$ alumina composite was almost the same as that of the $1.6 \mathrm{wt} \% \mathrm{CNF} /$ alumina composite. Actually, in the $5.0 \mathrm{wt} \%$ $\mathrm{CNF}$ /alumina composites, large alumina grains with $5-10 \mu \mathrm{m}$ existed in the regions where a few CNFs were distributed as 
shown in Fig. 3(f); however, such large grains were not caught in the measurement of alumina grain size because there were only a few such regions.

On the other hand, the $0.4 \mathrm{wt} \% \mathrm{CNF} /$ alumina composite sintered by PAS had a larger average alumina grain size than the $0.4 \mathrm{wt} \% \mathrm{CNF} /$ alumina composite sintered in vacuum and then treated by HIP; notably, the composites sintered by PAS at $1450^{\circ} \mathrm{C}$, as shown in Fig. $5(\mathrm{~b})$. That is, the unique sintering process of PAS accelerated the alumina grain boundary migration rate during sintering and the addition of $0.4 \mathrm{wt} \% \mathrm{CNFs}$ was not enough to retard the rapid grain boundary migrations during PAS. Consequently, 14, 17 and 20\% of CNFs entered alumina grains during PAS at 1300,1375 and $1450^{\circ} \mathrm{C}$, respectively, and alumina grains grew rapidly at $1450^{\circ} \mathrm{C}$, which was different behavior from the composite sintered in vacuum and then treated by HIP. ${ }^{17)}$ The grain growth behavior of the $0.8 \mathrm{wt} \% \mathrm{CNF} /$ alumina composites was similar to that of the $0.4 \mathrm{wt} \% \mathrm{CNF} /$ alumina composites.

In the $1.6 \mathrm{wt} \% \mathrm{CNF} /$ alumina composites in which $60 \%$ of CNFs distributed as solo, because not only solo CNFs but also CNF bundles distributed uniformly at grain boundaries of alumina, the rapid alumina grain boundary migrations during PAS was effectively retarded by such CNFs. Consequently, the $1.6 \mathrm{wt} \% \mathrm{CNF} /$ alumina composites had a smaller average alumina grain size with a narrower grain size distribution. In the 2.5 and $5.0 \mathrm{wt} \% \mathrm{CNF} /$ alumina composites sintered at $1375^{\circ} \mathrm{C}$, half of the CNFs and three-quarters of the CNFs formed bundles, respectively. The formed CNFs bundles made the grain growth retardation effect of the CNFs lower in these composites. Consequently, the average alumina grain size of the $2.5 \mathrm{wt} \%$ $\mathrm{CNF} /$ alumina composite was almost the same as that of the $1.6 \mathrm{wt} \% \mathrm{CNF} /$ alumina composite and that of the $5.0 \mathrm{wt} \% \mathrm{CNF} /$ alumina composite was slightly smaller than that of the $1.6 \mathrm{wt} \%$ $\mathrm{CNF} /$ alumina composite, though the alumina grain sizes of $\mathrm{CNT} /$ alumina composites generally decrease with an increase in the amount of CNTs. ${ }^{11), 13), 14), 25)}$

\subsection{Fracture toughness}

The fracture toughness of the $0.4-5.0 \mathrm{wt} \% \mathrm{CNF} /$ alumina composites sintered by PAS at $1300-1525^{\circ} \mathrm{C}$ for $80 \mathrm{~s}$ are shown in Fig. 7. In this study, the fracture toughness of the $1.6 \mathrm{wt} \%$ $\mathrm{CNF} /$ alumina composite sintered at $1300^{\circ} \mathrm{C}$ for $80 \mathrm{~s}$ was the highest $\left(5.4 \mathrm{MPa} \cdot \mathrm{m}^{0.5}\right)$, which was $54 \%$ higher than that of monolithic alumina $\left(3.5 \mathrm{MPa} \cdot \mathrm{m}^{0.5}\right)$. The fracture toughness of the composites increased with an increase in CNF content from 0 to $1.6 \mathrm{wt} \%$, showed a maximum at $1.6 \mathrm{wt} \%$ and decreased with an increase in CNF content from 1.6 to $5.0 \mathrm{wt} \%$. SEM images of Vickers cracks of the $0.4-5.0 \mathrm{wt} \% \mathrm{CNF} /$ alumina composites sintered at $1375^{\circ} \mathrm{C}$ for $80 \mathrm{~s}$ are shown in Fig. 8. Almost Vickers cracks on the CNFs/alumina composites were not deflected, but bridging and/or pull-out of CNFs were observed in the cracks, which means that the enhancement of the fracture toughness of the composites resulted from the bridging and/or pull-out of CNFs.

The relationship between fracture toughness and the average alumina grain size of the $\mathrm{CNF} /$ alumina composites is shown in Fig. 9. The fracture toughness of the composites tended to increase with a decrease in the average alumina grain size. The solid line in Fig. 9 is the curve for the relationship between fracture toughness and average alumina grain size of the $0.4 \mathrm{wt} \%$ AT05-CNF/alumina composites sintered in vacuum and then treated by HIP, which was shown in our previous study. ${ }^{17)}$ The fracture toughness of the $0.4-2.5 \mathrm{wt} \% \mathrm{CNF}$ /alumina composites were mostly fitted to the curve but those of the $5.0 \mathrm{wt} \% \mathrm{CNF} /$ alumina composite obviously deviated from the curve as indicated by a dotted circle in Fig. 9. The fracture toughness of the $5.0 \mathrm{wt} \% \mathrm{CNF} /$ alumina composite were lower than those of the 1.6 and $2.5 \mathrm{wt} \% \mathrm{CNF} /$ alumina composites even at the same average alumina grain size, which resulted from the formation of more CNF bundles in the $5.0 \mathrm{wt} \% \mathrm{CNF}$ /alumina composite. That is, the number of CNFs giving rise to the essential effect for bridging and/or pull-out was distinctly reduced in the $5.0 \mathrm{wt} \%$ $\mathrm{CNF}$ /alumina composite in which three-quarters the number of $\mathrm{CNFs}$ formed bundles. Consequently, the fracture toughness of the $5.0 \mathrm{wt} \% \mathrm{CNF} /$ alumina composite deviated from the curve.

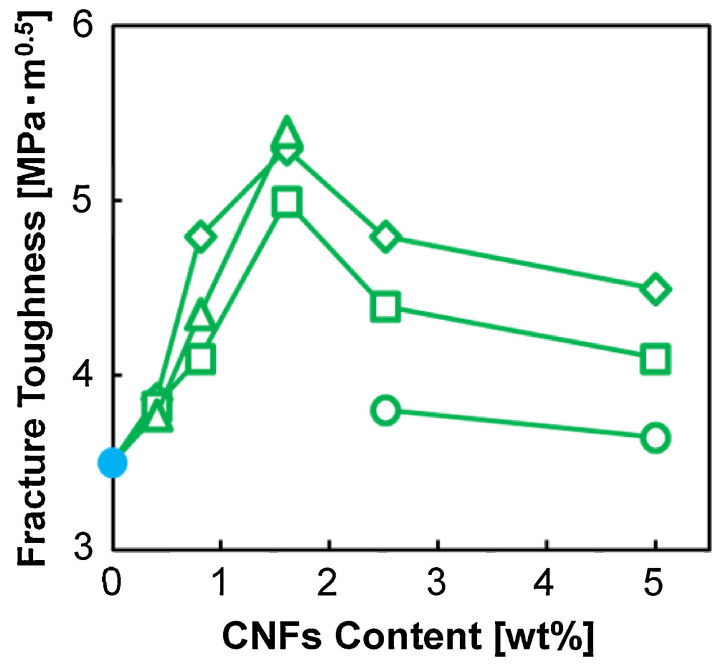

Fig. 7. Fracture toughness of the $0.4-5.0 \mathrm{wt} \% \mathrm{CNF} /$ alumina composites sintered by PAS at $(\triangle) 1300^{\circ} \mathrm{C},(\diamond) 1375^{\circ} \mathrm{C},(\square) 1450^{\circ} \mathrm{C}$ and (○) $1525^{\circ} \mathrm{C}$ for $80 \mathrm{~s}$, and that of $(\bigcirc)$ monolithic alumina sintered in air at $1300^{\circ} \mathrm{C}$ for $2 \mathrm{~h}$ and then treated by HIP.

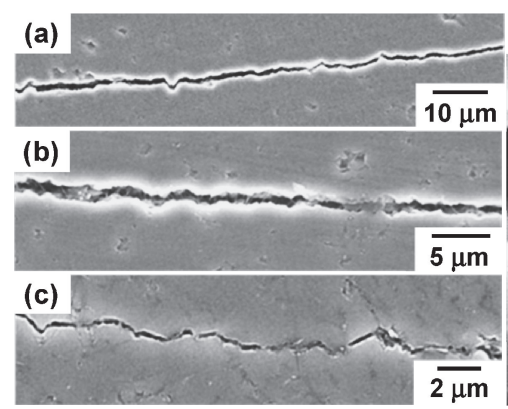

(d)

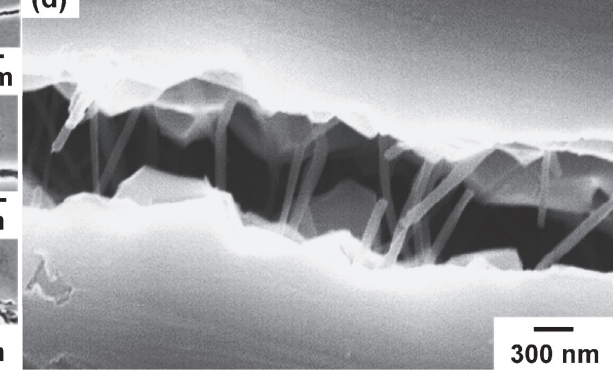

Fig. 8. SEM images of Vickers cracks on the (a) 0.4 , (b,d) 1.6 and (c) $5.0 \mathrm{wt} \% \mathrm{CNF} /$ alumina composites sintered by PAS at $1375^{\circ} \mathrm{C}$ for $80 \mathrm{~s}$. 


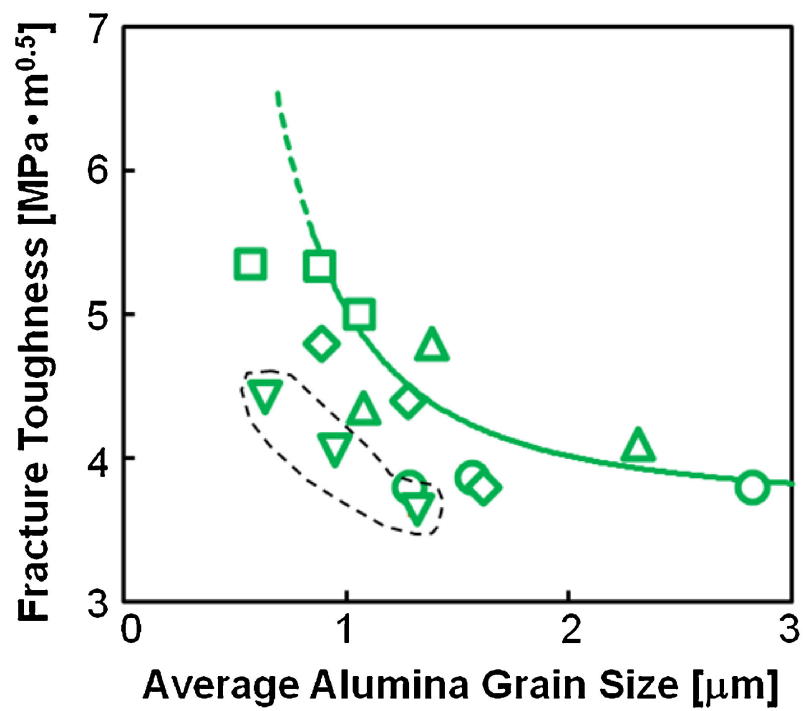

Fig. 9. Relationship between fracture toughness and average alumina grain size of the $(\bigcirc) 0.4,(\triangle) 0.8,(\square) 1.6,(\diamond) 2.5$ and $(\nabla) 5.0 \mathrm{wt} \%$ $\mathrm{CNF} /$ alumina composites sintered by $\mathrm{PAS}$ at various temperatures for $80 \mathrm{~s}$.

These results and those of our previous study ${ }^{17)}$ indicate that, while the fracture toughness of the composites was dependent on the surface state of the CNFs, ${ }^{17)}$ it was independent of the sintering method.

\section{Conclusions}

In this study, dense $0.4-5.0 \mathrm{wt} \% \mathrm{CNF} /$ alumina composites were fabricated using CNFs acid-treated for $0.5 \mathrm{~h}$ by PAS, and the influence of the additive amount of the CNFs on the CNFs distribution, the alumina grain size distribution and the fracture toughness of the composites were investigated.

The frequency of solo CNFs in the composites sintered by PAS at $1375^{\circ} \mathrm{C}$ decreased with an increase in the additive amount of CNFs. In the 0.4-1.6 wt \% CNF/alumina composites, the frequencies were $74-60 \%$. Also, there were regions where only a few CNFs were distributed and where many of the distributed CNFs were not observed in the composites. That is, the 0.4-1.6 wt \% CNFs could be mixed uniformly with alumina by a conventional ball-milling, with more than three-fifths the number of CNFs distributed individually, and those CNFs and CNF bundles distributed uniformly in the composites. As the additive amount of CNFs increased from 0.4 to $1.6 \mathrm{wt} \%$, the average alumina grain sizes and the alumina grain size distributions became smaller and narrower, respectively. 17 and $11 \%$ of CNFs entered alumina grains in the 0.4 and $0.8 \mathrm{wt} \% \mathrm{CNF}$ /alumina composites sintered at $1375^{\circ} \mathrm{C}$, while $96 \%$ of $\mathrm{CNFs}$ were distributed at the grain boundaries of alumina in the $1.6 \mathrm{wt} \% \mathrm{CNF}$ /alumina composite sintered at $1375^{\circ} \mathrm{C}$. That is, the addition of the 0.4 and $0.8 \mathrm{wt} \%$ $\mathrm{CNFs}$ was not enough to retard the alumina grain boundary migrations accelerated by PAS while the addition of $1.6 \mathrm{wt} \%$ CNFs effectively retarded rapid grain boundary migrations.

In the 2.5 and $5.0 \mathrm{wt} \% \mathrm{CNF} /$ alumina composites sintered at $1375^{\circ} \mathrm{C}$, half the number of CNFs and three-quarters the number of CNFs formed bundles, respectively. In addition, there were regions where only a few $\mathrm{CNFs}$ and many $\mathrm{CNFs}$ were distributed were observed in the composites. These results suggest that the 2.5 and $5.0 \mathrm{wt} \%$ CNFs could not be mixed uniformly by conventional ball-milling. The regions where only a few CNFs were distributed in the $5.0 \mathrm{wt} \% \mathrm{CNF} /$ alumina composites appeared clearly and were much wider than those in the $2.5 \mathrm{wt} \% \mathrm{CNF} /$ alumina composites. And alumina grains in such regions grew much larger, especially in the $5.0 \mathrm{wt} \% \mathrm{CNF} /$ alumina composites. In the regions where many $\mathrm{CNF}$ sere distributed, many $\mathrm{CNF}$ bundles had formed. The CNF bundles made the grain growth retardation effect of the $\mathrm{CNFs}$ lower. Consequently, the average alumina grain size of the 1.6-5.0 wt \% CNF/alumina composites was not greatly influenced by the additive amount of CNFs.

The fracture toughness of the composites increased with an increase in CNF content from 0.4 to $1.6 \mathrm{wt} \%$, reached a maximum for CNF content of $1.6 \mathrm{wt} \%$ and decreased as the CNF content increased from 1.6 to $5.0 \mathrm{wt} \%$. The maximum fracture toughness was $54 \%$ higher than the fracture toughness of monolithic alumina. The fracture toughness tended to increase with a decrease in the average alumina grain size; however, that of the $5.0 \mathrm{wt} \% \mathrm{CNF} /$ alumina composites in which three-quarters of the CNFs formed bundles obviously deviated from the relationship. This means that the number of CNFs giving rise to the essential effect for bridging and/or pull-out in $\mathrm{CNF} /$ alumina composites was distinctly reduced by forming more CNF bundles.

It is concluded in this study that, if more than $60 \%$ of CNFs can be distributed uniformly as solo at grain boundaries in the composites into which a large amount of CNFs is added, the composites with finer microstructures are obtained, which induces a drastic improvement in fracture toughness.

Acknowledgements This study was supported by a Grant-inAid for Scientific Research from the Ministry of Education, Culture, Sports, Science and Technology of Japan.

\section{References}

1) T. Hayashi, Y. A. Kim, T. Natsuki and M. Endo, ChemPhysChem, 8, 999-1004 (2007).

2) T. Xiao, Y. Ren, K. Liao, P. Wu, F. Li and H. M. Cheng, Compos. Sci. Technol., 68, 2937-2942 (2008).

3) A. H. Barber, I. K. Ashiri, S. R. Cohen, R. Tenne and H. D. Wagner, Compos. Sci. Technol., 65, 2380-2384 (2005).

4) C. Wei, K. Cho and D. Srivastava, Phys. Rev. B, 67, 115407 (2003).

5) M. F. Yu, O. Lourie, M. J. Dyer, K. Moloni, T. F. Kelly and R. S. Ruoff, Science, 287, 637-640 (2002).

6) M. Endo, Y. A. Kim, T. Hayashi, K. Nishimura, T. Matusita, K. Miyashita and M. S. Dresselhaus, Carbon, 39, 1287-1297 (2001).

7) M. F. Yu, B. S. Files, S. Arepalli and R. S. Ruoff, Phys. Rev. Lett., 84, 5552-5555 (2000).

8) J. P. Salvetat and A. J. Kulik, Adv. Mater., 11, 161-165 (1999).

9) N. Ueda, T. Yamakami, T. Yamaguchi, K. Kitajima, Y. Usui, K. Aoki, T. Nakanishi, F. Miyaji, M. Endo, N. Saito and S. Taruta, J. Ceram. Soc. Japan, 118, 847-854 (2010).

10) S. Sarkar and P. Kr. Das, Ceram. Int., 38, 423-432 (2012).

11) I. Ahmad, H. Cao, H. Chen, H. Zhao, A. Kennedy and Y. Q. Zhu, J. Eur. Ceram. Soc., 30, 865-873 (2010).

12) G. Yamamoto, M. Omori, K. Yokomizo, T. Hashida and K. Adachi, Mater. Sci. Eng., B, 148, 265-269 (2008).

13) G. Yamamoto, M. Omori and H. Kimura, Nanotechnology, 19, 315708 (2008).

14) K. Hirota, Y. Takaura, M. Kato and Y. Miyamoto, J. Mater. Sci., 42, 4792-4800 (2007).

15) S. Maensiri, P. Laokul, J. Klinkaewnarong and V. Amornkitbamrung, Mater. Sci. Eng., A, 447, 44-50 (2007).

16) J. Sun, M. Iwasa, T. Nakayama, K. Niihara, L. Gao and X. Jin, J. Ceram. Soc. Japan, 112, S403-S406 (2004).

17) N. Ueda, T. Yamakami, T. Yamaguchi, K. Kitajima, Y. Usui, K. Aoki, M. Endo, N. Saito and S. Taruta, J. Ceram. Soc. Japan, 120, 560-568 (2012). 
18) K. Niihara, R. Morena and D. P. H. Hasselman, "Fracture Mechanics of Ceramics”, Ed. by R. C. Bradt, A. G. Evans, P. P. Hasselman and F. F. Lange, Plenum, New York (1983) pp. 97105.

19) K. Niihara, R. Morena and D. P. H. Hasselman, J. Mater. Sci. Lett., 1, 13-16 (1982).

20) K. Niihara, R. Morena and D. P. H. Hasselman, J. Am. Ceram. Soc., 65, C-116 (1982).

21) T. Miyoshi, N. Sagawa and T. Sasa, J. Jpn. Soc. Mech. Eng. A, 51, 2489-2497 (1985) [in Japanese].
22) Ceram. Soc. Japan, "Characterization of Ceramics" (1987) pp. 58 [in Japanese].

23) E. E. Underwood, A. R. Colcord and W. C. Wangh, "Ceramic microstructures" Ed. by J. A. Pask and R. M. Fulrath, Wiley and Sons, Berkeley (1966) pp. 25-52.

24) E. E. Underwood, "Quantitative stereology", Addison Wesley (1970).

25) F. Inam, H. Yan, T. Peijs and M. J. Reece, Compos. Sci. Technol., 70, 947-952 (2010). 